www.jmscr.igmpublication.org

Impact Factor 5.84

Index Copernicus Value: 83.27

ISSN (e)-2347-176x ISSN (p) 2455-0450

crossref DOI: https://dx.doi.org/10.18535/jmscr/v5i1.126

Journal Of Medical Science And Clinical Research

\title{
Comparative Study of Analgesic and Hemodynamic Effects of Intrathecal Administration of $0.75 \%$ Ropivacaine and Dexmedetomidin with $0.75 \%$ Ropivacaine alone in Elective Lower Limb Orthopaedic Surgeries
}

\author{
Authors \\ Dr Archana $\mathbf{M}^{1}$, Dr Gangadhar ${ }^{2}$ \\ ${ }^{1}$ MBBS, DNB, Anesthesia, Senior Resident, Department of Anesthesiology,Sri Siddartha Medical College, \\ Tumkur \\ ${ }^{2}$ MBBS, MD,F.I.C.A, Professor and HOD, Dept of Anesthesiology,Sri Siddartha Medical College, Tumkur
}

\begin{abstract}
Background: Dexmedetomidine, a selective $\alpha 2$-adrenergic agonistic provides additional analgesic action along with local anaesthetics in spinal anaesthesia.

Aims and Objectives: To assess the analgesic and hemodynamic effects of intrathecal administration of Ropivacaine 0.75\% alone versus Ropivacaine 0.75\% with $5 \mathrm{mcg}$ of Dexmedetomidine in elective lower limb orthopedic surgeries.

Material and Methods: After approval of ethical committee, 120 patients who were scheduled for elective lower limb orthopedic surgeries were selected and randomized in 2 groups: In, Group 1, 3 ml volume of $0.75 \%$ isobaric Ropivacaine with $0.5 \mathrm{ml}$ normal saline to make $3.5 \mathrm{ml}$, was administered. In Group $2,3 \mathrm{ml}$ volume of $0.75 \%$ isobaric Ropivacaine with $5 \mu \mathrm{g}$ Dexmedetomidine to make a volume of $3.5 \mathrm{ml}$ was administered. Onset of sensory block, analgesic effects and hemodynamic effects were compared between the 2 groups.
\end{abstract}

Results: Onset of sensory bock was $5.17 \pm 0.7$ minutes for only Ropivacaine group and $4.63 \pm 0.61$ for Ropivacaine with Dexmedetomidine group. Time taken by block to reach maximum level was $11.87 \pm 1.36$ minutes for only Ropivacaine group and $11.68 \pm 1.24$ minutes for Ropivacaine with Dexmedetomidine group. Time taken by block for two segment regression from highest sensory level was $65.3 \pm 1.68$ minutes for only Ropivacaine group and $125.87 \pm 1.74$ minutes for Ropivacaine with Dexmedetomidine group. Mean time of required for first dose of rescue analgesia was $244.33 \pm 2.83$ minutes for only Ropivacaine group and $466.23 \pm 2.4$ minutes for Ropivacaine with Dexmedetomidine group. Mean Highest pain score on VAS was $4.9 \pm 0.8$ for only Ropivacaine group and $3.8 \pm 0.66$ for Ropivacaine with Dexmedetomidine group. Number of Diclofenac injections in first 24 hrs postoperatively was $3.73 \pm 0.64$ for only Ropivacaine group and $1 \pm 0.59$ for Ropivacaine with Dexmedetomidine group. Blood pressure and Heart rate were significantly lower in Ropivacaine with Dexmedetomidine group compared to only Ropivacaine group .

Conclusion: Dexmedetomidine $(5 \mu \mathrm{g})$ as an adjunct to Ropivacaine is superior to Ropivacaine alone in intrathecal analgesia. It augments onset of action, prolongs sensory blockade and reduces requirement rescue analgesics. Its hemodynamic side effects can be treated with vasopressors. 


\section{Introduction}

Spinal anaesthesia, is a conventional regional anaesthetic technique with acceptable safetyefficacy profile in lower abdominal and lower limb surgeries. There have been attempt to improve efficacy of Spinal anaesthesia by addition of various adjuncts. Dexmedetomidine, a selective $\alpha 2$-adrenergic agonistic action with prolonged $n$ sensory blockade and enhanced analgesic effects holds a future as an adjunct along with local anaesthetics in spinal anaesthesia

Lower abdominal and lower limb surgeries may be performed under local, regional (spinal or epidural) or general anesthesia. Spinal block is still the first choice because of its rapid onset, superior blockade, low risk of infection as from catheter in situ, less failure rates and costeffectiveness, but has the drawbacks of shorter duration of block and lack of adequate postoperative analgesia ${ }^{(1)}$.

Till recently Bupivacaine 0.5\% Heavy was the only drug used for spinal anaesthesia after the discontinuation of Lidocaine's intrathecal use. Ropivacaine- another amino-amide local anaesthetic having all the advantages but with lower CNS and cardiac toxicity of Bupivacaine has been introduced ${ }^{(2)}$. Ropivacaine is a first single enantiomer-specific compound, which has a reduced risk of cardiotoxicity, neurotoxicity, and rapid recovery of motor function ${ }^{(3)}$. Ropivacaine is available as $0.75 \%$ isobaric and $0.5 \%$ isobaric for intrathecal anaesthesia. Thus Ropivacaine is a new long acting local anaesthetic whose neuronal blocking potential seems to be equal or superior to Bupivacaine $^{(4)}$.

Postoperative pain relief is an important issue with Ropivacaine. In recent years, use of intrathecal adjuvant has gained popularity with the aim of prolonging the duration of block, better success rate, patient satisfaction, decreased resource utilization compared with general anaesthesia and faster recovery. Adequate pain management is essential to facilitate rehabilitation and accelerate functional recovery, enabling patients to return to their normal activity more quickly. The quality of the spinal anaesthesia has been reported to be improved by the addition of opioids (such as morphine, fentanyl and sufentanil) and other drugs (such as dexmedetomidine, clonidine, magnesium sulfate, neostigmine, ketamine and midazolam), but no drug to inhibit nociception is without associated adverse effects.

Dexmedetomidine, a new highly specific, potent and selective $\alpha 2$-adrenoceptor agonist, as a neuraxial adjuvant as it provides stable hemodynamic conditions, good quality of intraoperative and prolonged postoperative analgesia with minimal side effects ${ }^{(5)}$. Based on earlier human studies, it is hypothesized that intrathecal $5 \mu \mathrm{g}$ dexmedetomidine would produce more postoperative analgesic effect in spinal anaesthesia with minimal side effects which reduces opioids and inhalational anesthetic requirement. Intrathecal alfa-2 receptor agonists have antinociceptive action for both somatic and visceral pain.

Present study intends to evaluate the synergistic effect and safety of Dexmedetomidine and Ropivacaine $0.75 \%$ in spinal anaesthesia and in comparison to $0.75 \%$ Ropivacaine alone.

\section{Aims and Objectives}

To assess the analgesic and hemodynamic effects of intrathecal administration of Ropivacaine $0.75 \%$ alone versus Ropivacaine $0.75 \%$ with $5 \mathrm{mcg}$ of Dexmedetomidine in elective lower limb orthopedic surgeries

\section{Material and Methods}

After obtaining institutional Ethical Committee approval and written informed consent, 60 adult patients of the American Society of Anaesthesiologists (ASA) grade I and II, aged 18-60 years, of both sexes, Weight $>50 \mathrm{~kg}$, Height $>150 \mathrm{~cm}$ and scheduled to undergo elective lower limb orthopedic surgeries under spinal anaesthesia were included in this randomized, prospective, doubleblinded study.

Based on previous studies and statistical formula, a sample size of 30 in each group was 
determined with an alpha error of 0.05 and power of 0.95 in each group (60). The patients were allocated into two groups of 30 patients each by a computer-generated randomization table to receive the study drugs as follows:

1. Group 1: $3 \mathrm{ml}$ volume of $0.75 \%$ isobaric Ropivacaine with $0.5 \mathrm{ml}$ normal saline to make $3.5 \mathrm{ml}$

2. Group 2: $3 \mathrm{ml}$ volume of $0.75 \%$ isobaric Ropivacaine with $5 \mu \mathrm{g}$ Dexmedetomidine to make a volume of $3.5 \mathrm{ml}$

Patient with Pregnancy and lactation, Obesity, hypertension or Diabetes mellitus, local infection, severe hypovolemia, bleeding coagulopathy, neurological disorder, raised intra cranial tension and deformities of spine, allergy to local anaesthetics and dexmedetomidine were excluded from the study.

Each patient was visited pre-operatively and the procedure explained and written and informed consent to be obtained. All the routine investigations required for pre operative evaluation and the proposed surgery was done. No premedication was given as it may interfere with assessment of haemodynamic data and drugs acting on heart rate and blood pressure were avoided preoperatively. Patients were allowed for a period of absolute fasting of at least 6 hours.

On the day of scheduled surgery, patients were wheeled to operating room.Intravenous line was be secured with $18 \mathrm{G}$ Intravenous cannula and patients was preloaded with lactated ringer's solution at $15 \mathrm{ml} / \mathrm{kg}$. Under aseptic and antiseptic precaution, lumbar puncture was performed at $\mathrm{L}_{3-}$ ${ }_{4}$ intervertebral space using midline approach with a 25G Quincke spinal needle in the skitting position and either of the study drugs was administered intrathecally using the randomization table. The study solution was prepared by a colleague not involved in the study to achieve blinding.

Immediately after completion of the block, patients will be made to lie in the supine position. Oxygen was administrated through a mask if the pulse oximetry reading decreased below $90 \%$. Hypotension defined as a decrease in systolic blood pressure by more than $30 \%$ from baseline or less than $80 \mathrm{~mm} \mathrm{Hg}$ was treated with incremental intravenous doses of ephedrine $6 \mathrm{mg}$ and further intravenous fluid as required. Bradycardia defined as heart rate less than 50 beats per minute was treated with intravenous atropine $0.6 \mathrm{mg}$.

Sensory testing was assessed by loss of sensation to pinprick with $23 \mathrm{G}$ hypodermic needle . Onset and dermatomal levels were tested every 2 minutes until the highest level had stabilized for four consecutive tests. Testing was done every 10 minutes until the point of two segment regression of the block. Data regarding the time to reach highest dermatomal level of sensory blockade from the time of injection, time for two segment sensory regression will was collected.

After the surgery, patients was be shifted to the post anaesthesia care and recovery unit and monitored until there is complete recovery of sensory and motor blockade. Postoperatively vital parameters will be recorded every 15 minutes, and also any adverse events like nausea, vomiting, pruritus, shivering etc will be noted. Postoperatively, pain scores were recorded by using Visual Analogue Score between 0 and $10(0=$ no pain, $10=$ the most severe pain $)$ .initially every 1 hour for 2 hours ,then every 2 hours for next 8 hours and then after every 4 hours for next 24 hours. Injection Diclofenac sodium $75 \mathrm{mg}$ intramuscular was given as rescue analgesia when Visual Analogue Score was 4 or more than 4.Followup was carried out one week postoperatively for headache ,pain and dysesthesias in buttocks, thighs, or lower limbs.

\section{Statistical Methods}

In the statistical analysis of our study, Continuous variables were presented as mean for parametric data and median if the data is non parametric or skewed. Student $t$ test was applied for calculation of statistical significance whenever the data followed normative distribution. Mann whitney test was applied whenever data followed non 


\section{JMSCR Vol||05||Issue||01||Pages 16023-16032||January}

normative distribution. Categorical variables was expressed as frequencies and percentages. Nominal categorical data between the groups was compared using Chi-square test or Fisher's exact test as appropriate. $\mathrm{P}<0.05$ was taken to indicate a statistically significant difference. Minitab version 17 was used for computation of statistics.

\section{Results}

The groups were comparable with respect to age, height, weight and ASA physical status. The results regarding the characteristics of sensory block are summarised. Onset of sensory bock was $5.17 \pm 0.7$ minutes for only Ropivacaine group and $4.63 \pm 0.61$ for Ropivacaine with Dexmedetomidine group. Time taken by block to reach maximum level was $11.87 \pm 1.36$ minutes for only Ropivacaine group and $11.68 \pm 1.24$ minutes for Ropivacaine with Dexmedetomidine group. Time taken by block for two segment regression from highest sensory level was $65.3 \pm$ 1.68 minutes for only Ropivacaine group and $125.87 \pm 1.74$ minutes for Ropivacaine with Dexmedetomidine group. Mean time of required for first dose of rescue analgesia was $244.33 \pm$ 2.83 minutes for only Ropivacaine group and $466.23 \pm 2.4$ minutes for Ropivacaine with Dexmedetomidine group. Mean Highest pain score on VAS was $4.9 \pm 0.8$ for only Ropivacaine group and $3.8 \pm 0.66$ for Ropivacaine with Dexmedetomidine group. Number of Diclofenac injections in first $24 \mathrm{hrs}$ postoperatively was 3.73 \pm 0.64 for only Ropivacaine group and $1 \pm 0.59$ for Ropivacaine with Dexmedetomidine group. Blood pressure and Heart rate were significantly lower in Ropivacaine with Dexmedetomidine group compared to only Ropivacaine group .There was no serious complication like nausea, vomiting, shivering, itching, pruritus, sedation, respiratory depression.

Table 1. Demographic Characteristics of the study Groups

\begin{tabular}{|l|c|c|c|c|c|}
\hline \multirow{2}{*}{ Variables } & \multicolumn{2}{|c|}{ Only Ropivacaine Group } & \multicolumn{2}{c|}{ Ropivacaine with Dexmedetomidine Group } \\
\cline { 2 - 6 } & Mean & SD value & Mean & \multicolumn{2}{c|}{ SD } \\
\hline Age & 40.47 & 10.78 & 39.43 & 11.07 & 0.72 \\
\hline $\begin{array}{l}\text { Height } \\
(\mathrm{cm})\end{array}$ & 163.2 & 6.6 & 161.07 & 0.21 \\
\hline $\begin{array}{l}\text { Weight } \\
(\mathrm{kg})\end{array}$ & 57.97 & 5.94 & 52.43 & 4.22 & 0 \\
\hline
\end{tabular}

Table 2. Onset and Duration of spinal block

\begin{tabular}{|l|c|c|c|c|c|c|}
\hline \multirow{2}{*}{ Variables } & \multicolumn{2}{|c|}{ Only Ropivacaine Group } & \multicolumn{2}{c|}{$\begin{array}{c}\text { Ropivacaine with } \\
\text { Dexmedetomedine Group }\end{array}$} & \multirow{2}{*}{ Significance } \\
\cline { 2 - 6 } & Mean & SD & Mean & Significance & value \\
\hline Onset of sensory bock(min) & 5.17 & 0.7 & 4.63 & Significance & 0.04 & Significant \\
\hline $\begin{array}{l}\text { Time required for } \\
\text { maximum bock(min) }\end{array}$ & 12.87 & 1.36 & 11.68 & Significance & 0.045 & Significant \\
\hline $\begin{array}{l}\text { Time required for two } \\
\text { segment regression from } \\
\text { highest sensory evel }\end{array}$ & 65.3 & 1.68 & 125.87 & Significance & 0.00 & Significant \\
\hline
\end{tabular}




\section{JMSCR Vol||05||Issue||01||Pages 16023-16032||January}

Diagram .1. Onset and Duration of spinal block

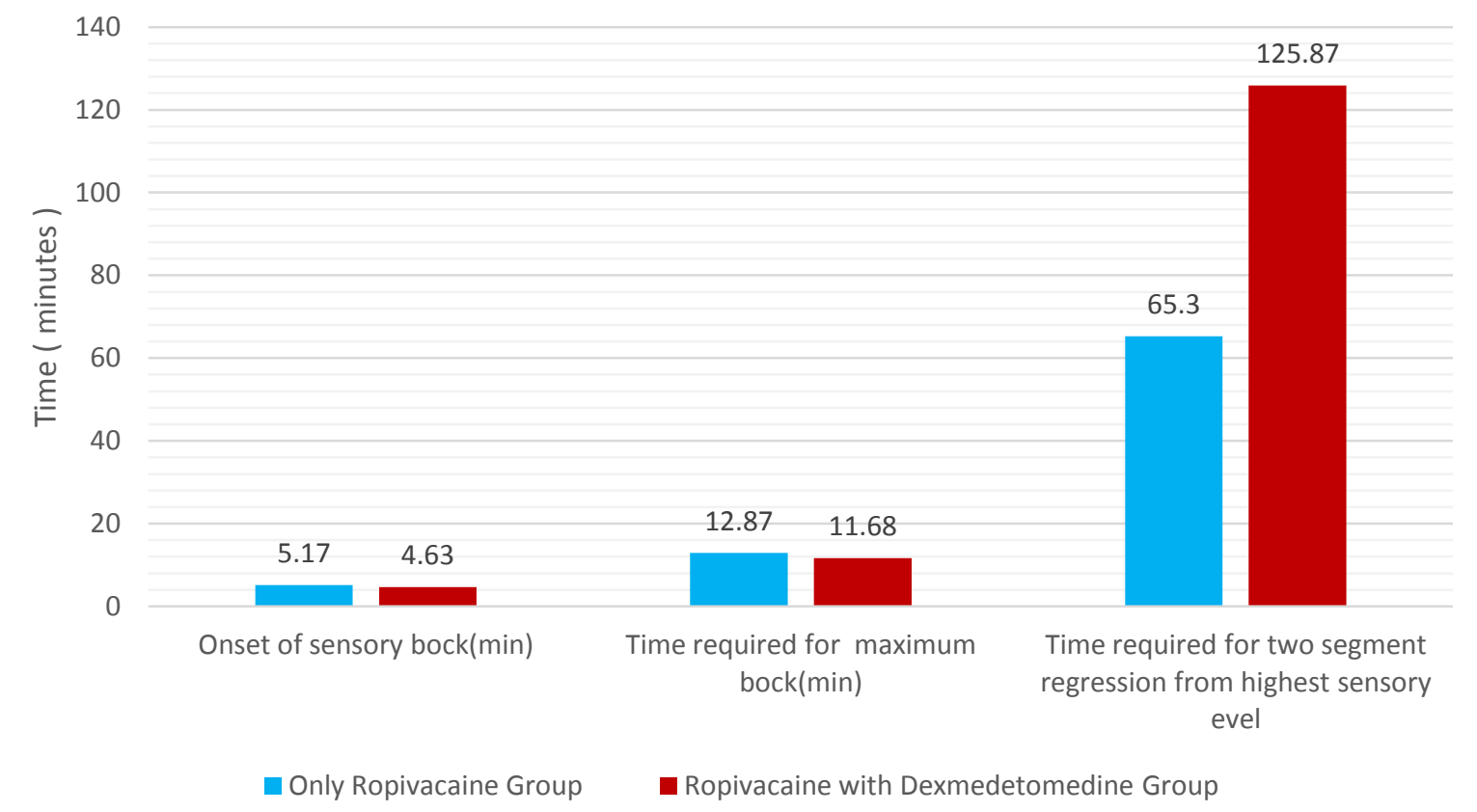

Table 3.Effects on Analgesia

\begin{tabular}{|l|c|c|c|c|c|c|}
\hline \multirow{2}{*}{ Variables } & \multicolumn{2}{|c|}{ Only Ropivacaine Group } & \multicolumn{2}{c|}{$\begin{array}{c}\text { Ropivacaine with } \\
\text { Dexmedetomedine Group }\end{array}$} & P Value & \multirow{2}{*}{ Significance } \\
\cline { 2 - 5 } & Mean & SD & Mean & SD & & \\
\hline $\begin{array}{l}\text { Time before administration of } 1^{\text {st }} \\
\text { dose of rescue Analgesia (hours) }\end{array}$ & 4.07 & 2.83 & 7.77 & 2.4 & 0.00 & Significant \\
\hline Highest pain score on VAS & 4.9 & 0.8 & 3.8 & 0.66 & 0.00 & Significant \\
\hline $\begin{array}{l}\text { Number of Diclofenac injections in } \\
\text { first 24 hrs postoperatively }\end{array}$ & 3.73 & 0.64 & 1 & 0.59 & 0.00 & Significant \\
\hline
\end{tabular}

Diagram 2.Effects on Analgesia

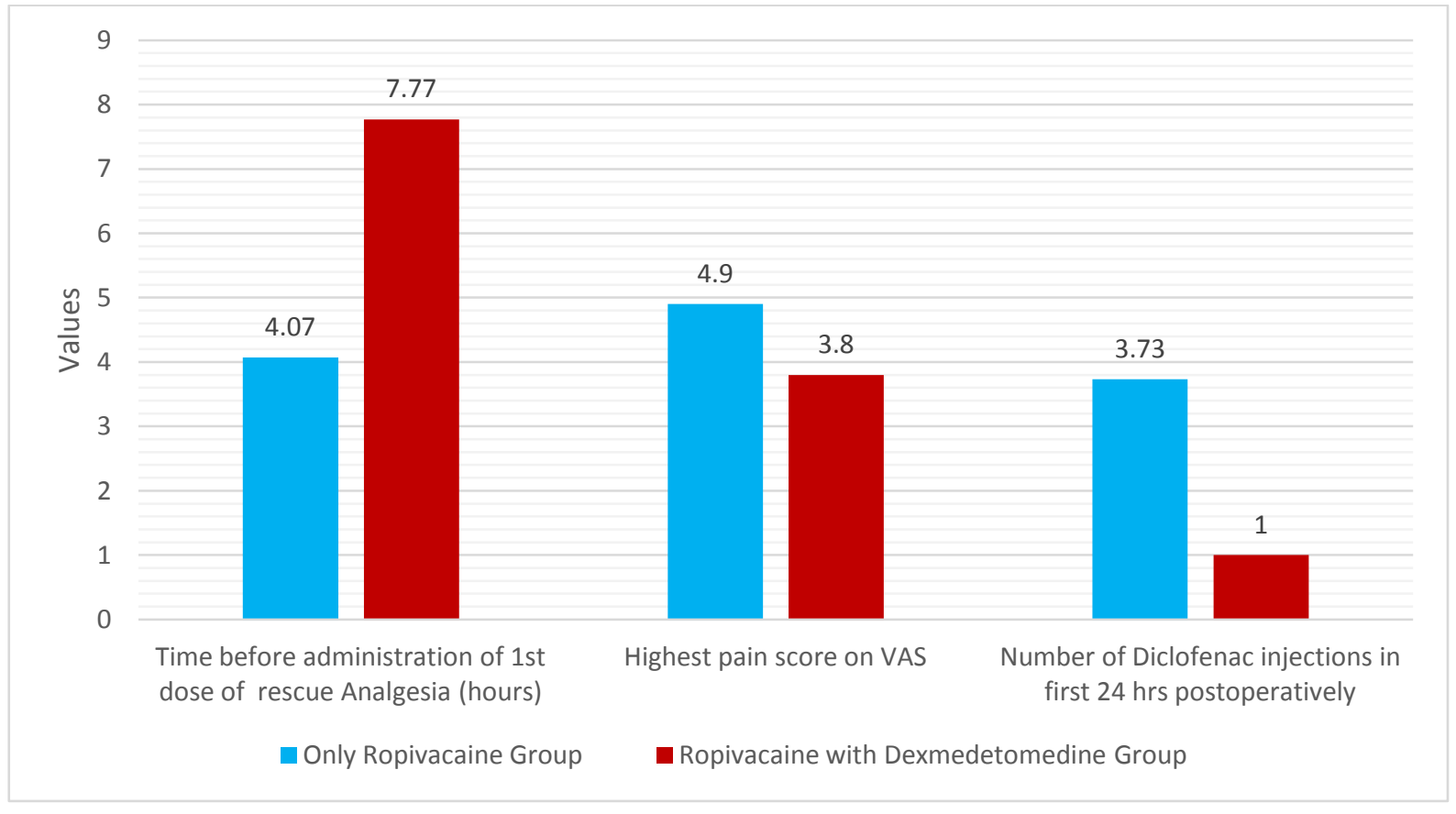


Table 4. Effects on Systolic Blood Pressure

\begin{tabular}{|l|c|c|c|c|c|}
\hline \multirow{2}{*}{ Time Interval } & \multicolumn{2}{|c|}{ Only } & \multicolumn{2}{c|}{$\begin{array}{c}\text { Ropivacaine with } \\
\text { Dexmedetomedine Group }\end{array}$} & p value \\
\cline { 2 - 6 } & Mean & SD & Mean & SD & \\
\hline Baseline & 123.31 & 7.73 & 125.38 & 6.28 & 0.27 \\
\hline $2 \mathrm{~min}$ & 115.31 & 6.89 & 111.66 & 6.03 & 0.04 \\
\hline $5 \mathrm{~min}$ & 112.07 & 4.19 & 107.79 & 4.67 & 0.00 \\
\hline $10 \mathrm{~min}$ & 111.93 & 5.49 & 107.38 & 3.67 & 0.00 \\
\hline $20 \mathrm{~min}$ & 116.34 & 6.33 & 108.83 & 5.36 & 0.00 \\
\hline $30 \mathrm{~min}$ & 118.79 & 5.43 & 109.31 & 4.94 & 0.00 \\
\hline $60 \mathrm{~min}$ & 118.69 & 6.46 & 113.24 & 4.67 & 0.00 \\
\hline $120 \mathrm{~min}$ & 121.17 & 5.33 & 113.72 & 4.71 & 0.00 \\
\hline $180 \mathrm{~min}$ & 122.14 & 5.97 & 115.93 & 4.83 & 0.00 \\
\hline
\end{tabular}

Diagram.3. Effects on Systolic Blood Pressure

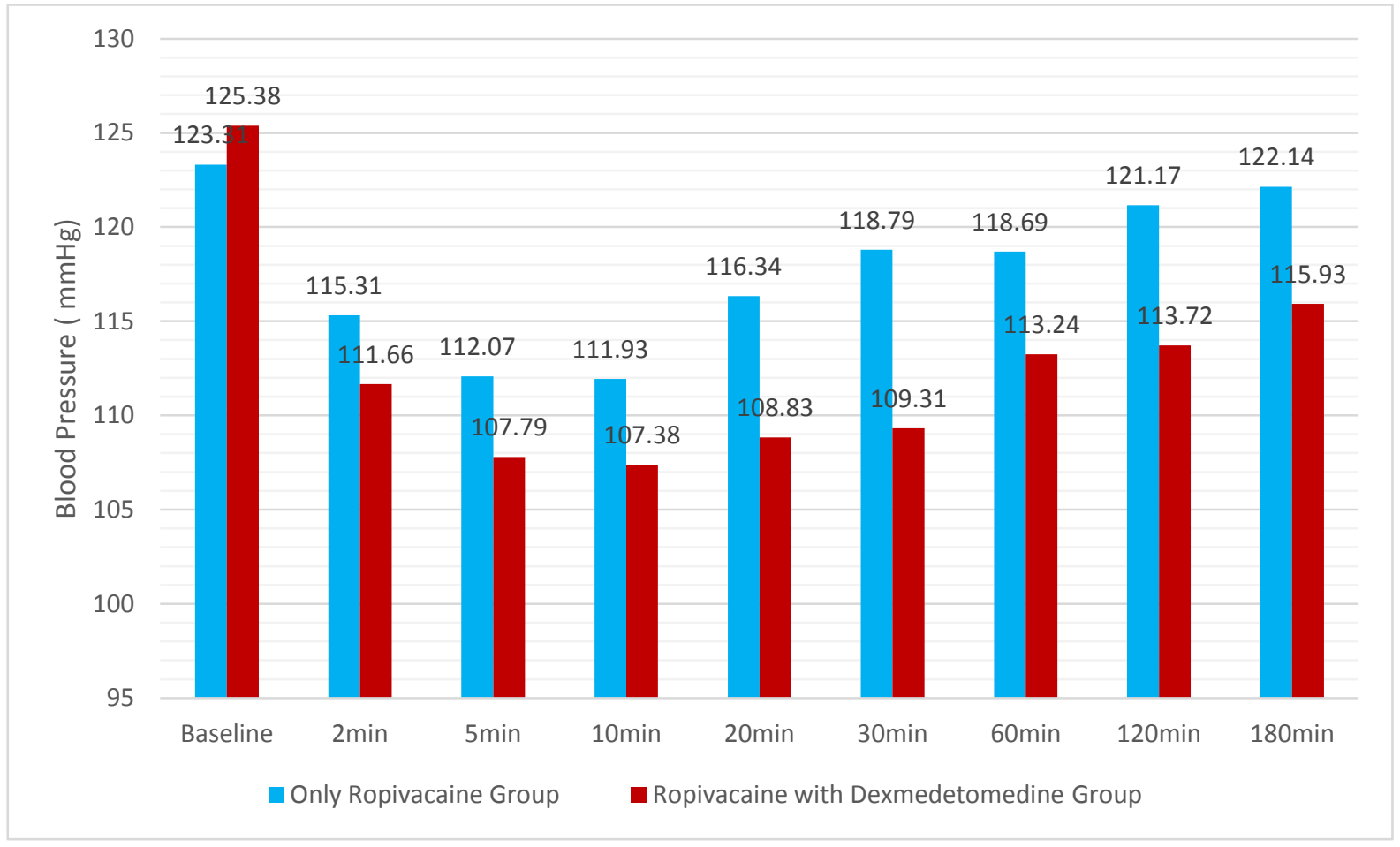

Table 5. Effects on Diastolic Blood Pressure

\begin{tabular}{|l|c|c|c|c|c|}
\hline \multirow{2}{*}{ Time Interval } & \multicolumn{2}{|c|}{ Only } & \multicolumn{2}{c|}{$\begin{array}{c}\text { Ropivacaine with } \\
\text { Dexmedetomedine Group }\end{array}$} & \multirow{2}{*}{ p value } \\
\cline { 2 - 5 } & Mean & SD & Mean & SD & pacaine Group \\
\hline Baseline & 78.41 & 5.03 & 80.41 & 4.67 & 0.12 \\
\hline $2 \mathrm{~min}$ & 74.41 & 3.44 & 72.83 & 5.46 & 0.19 \\
\hline $5 \mathrm{~min}$ & 72.69 & 5.02 & 69.59 & 6.17 & 0.04 \\
\hline $10 \mathrm{~min}$ & 72.55 & 3.85 & 67.10 & 5.41 & 0.00 \\
\hline $20 \mathrm{~min}$ & 71.86 & 4.03 & 68.48 & 4.95 & 0.01 \\
\hline $30 \mathrm{~min}$ & 72.28 & 4.23 & 70.55 & 5.40 & 0.04 \\
\hline $60 \mathrm{~min}$ & 73.59 & 2.95 & 71.45 & 5.12 & 0.03 \\
\hline $120 \mathrm{~min}$ & 73.93 & 4.88 & 72.55 & 4.27 & 0.04 \\
\hline $180 \mathrm{~min}$ & 76.69 & 4.35 & 73.59 & 4.26 & 0.01 \\
\hline
\end{tabular}


Diagram 4. Effects on Diastolic Blood Pressure

85

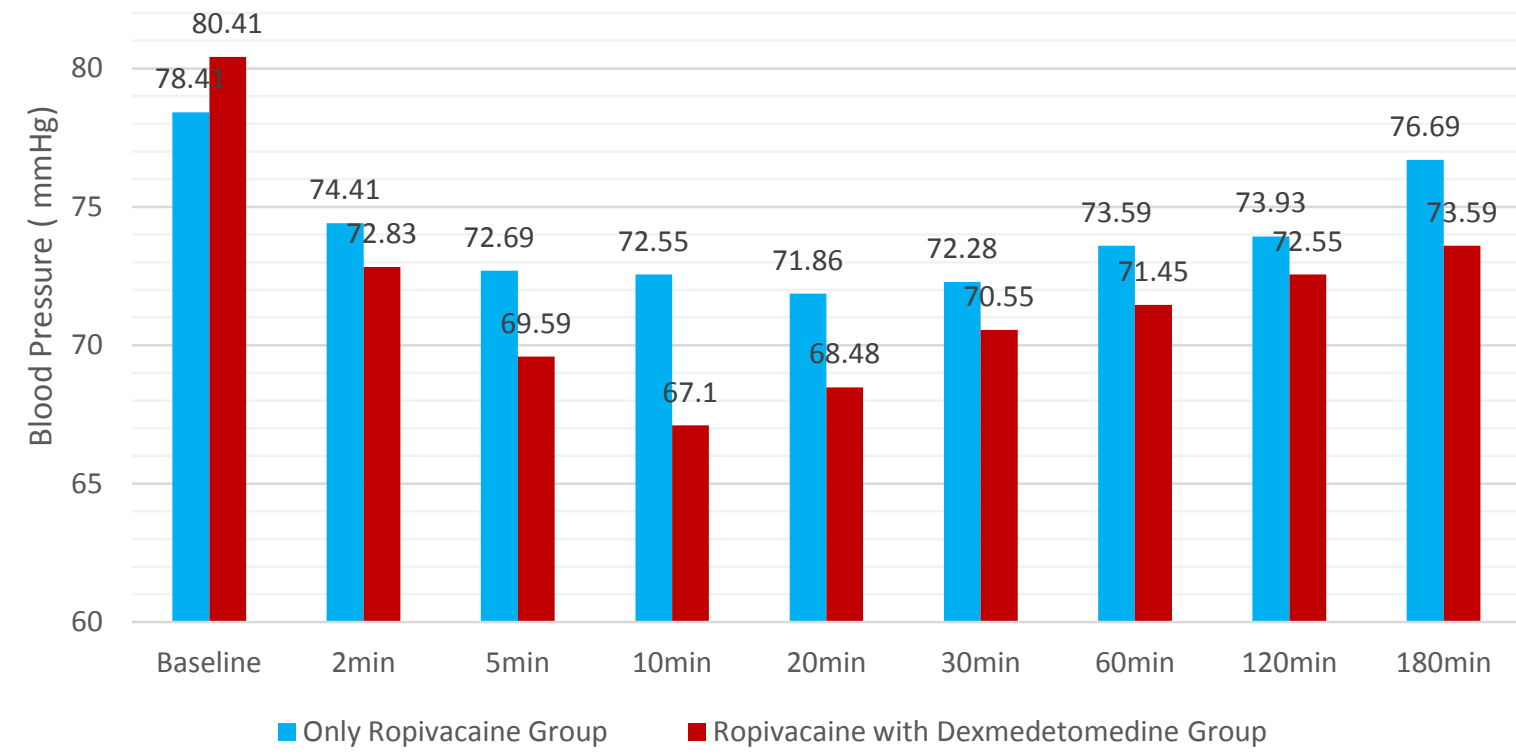

Table 6. Effects on Heart Rate

\begin{tabular}{|l|c|c|c|c|c|}
\hline \multirow{2}{*}{ Time Interval } & \multicolumn{2}{|c|}{ Only } & \multicolumn{2}{c|}{$\begin{array}{c}\text { Ropivacaine with } \\
\text { Dexmedetomedine Group }\end{array}$} & \multirow{2}{*}{ p value } \\
\cline { 2 - 5 } & Mean & SD & Mean & SD & p \\
\hline Baseline & 84.86 & 5.76 & 80.97 & 7.04 & 0.03 \\
\hline $2 \mathrm{~min}$ & 81.68 & 4.15 & 80.17 & 7.04 & 0.25 \\
\hline $5 \mathrm{~min}$ & 80.45 & 4.49 & 76.41 & 7.21 & 0.01 \\
\hline $10 \mathrm{~min}$ & 78.34 & 5.37 & 74.79 & 6.46 & 0.01 \\
\hline $20 \mathrm{~min}$ & 78.28 & 7.03 & 70.62 & 6.29 & 0.00 \\
\hline $30 \mathrm{~min}$ & 79.93 & 6.39 & 73.93 & 5.25 & 0.00 \\
\hline $60 \mathrm{~min}$ & 81.83 & 4.48 & 76.41 & 5.18 & 0.00 \\
\hline $120 \mathrm{~min}$ & 83.48 & 4.73 & 78.07 & 4.43 & 0.00 \\
\hline $180 \mathrm{~min}$ & 84.31 & 3.85 & 80.21 & 4.14 & 0.00 \\
\hline
\end{tabular}

Diagram 5. Effects on Heart Rate

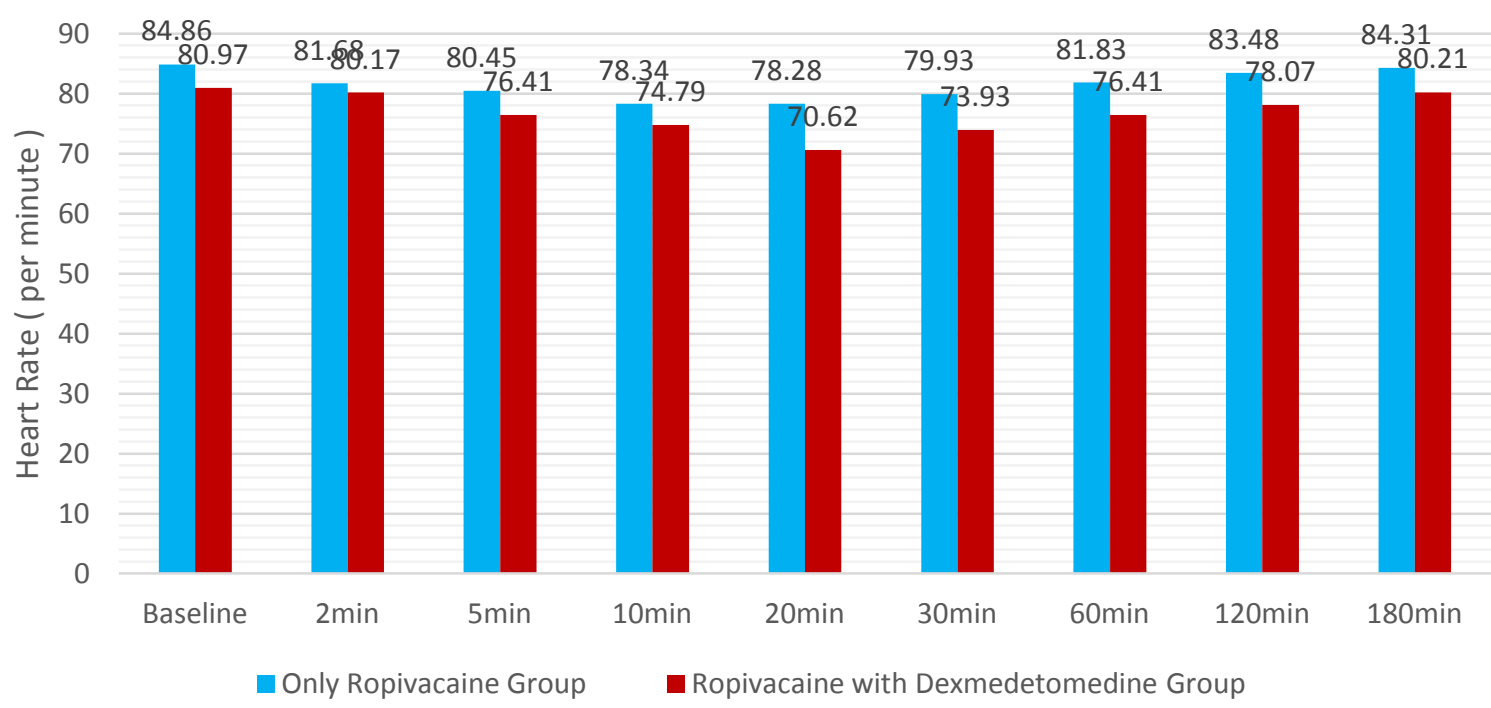




\section{Discussion}

Various adjunct have been tried with local anaesthetic agents for subarachnoid blockade. Dexmedetomidine, the pharmacologically active $\mathrm{d}$-isomer of medetomidine is a highly specific and selective $\alpha 2$ adrenoceptor agonist with $\alpha 2: \alpha 1$ binding selectivity ratio of $1620: 1$ as compared to 220:1 for clonidine, thus decreasing the unwanted side effects of $\alpha 1$ receptors. Presynaptic activation of $\alpha 2$ adrenoceptor in central nervous system (CNS) inhibits the release of norepinephrine, terminating the propagation of pain signals and their postsynaptic activation inhibits sympathetic activity, thereby decreasing HR and BP. Transient hypertensive response is sometimes noted due to to initial stimulation of $\alpha-2 B$ subtype receptors in vascular smooth muscles. As a reflex response, bradycardia ensues. and may persists subsequently due to prolonged central sympathetic inhibition. However, and HR response Baroreceptor reflex to a vasopressor pressor agent is well preserved with the use of dexmedetomidine. It is High selectivity for $\alpha-2 \mathrm{~A}$ receptors which mediates sedation, analgesia, and anxiolytics. Previous research shows encouraging results for its use in sub arachnoid block.

\section{Onset and duration of block}

In our study, onset of sensory bock was $5.17 \pm 0.7$ minutes for only Ropivacaine group and $4.63 \pm$ 0.61 for Ropivacaine with Dexmedetomidine group. This difference was statistically significant. In a similar study by Alka Shah et al (2012), onset of sensory bock for Ropivacaine with Dexmedetomidine was $4.8 \pm 1.2$ minutes, which was comparable to our study .

Time taken by block to reach maximum level was $12.87 \pm 1.36$ minutes for only Ropivacaine group and $11.68 \pm 1.24$ minutes for Ropivacaine with Dexmedetomidine group. This finding was statistically significant. In study by Alka Shah et al, time taken by block to reach maximum level was $11.7 \pm 1.7$, which was comparable to our study .
Time taken by block for two segment regression from highest sensory level was $65.3 \pm 1.68$ minutes for only Ropivacaine group and 125.87 $\pm \quad 1.74$ minutes for Ropivacaine with Dexmedetomidine group in our study. This difference was statistically significant. In study by Alka Shah et al, time taken by block for two segment regression from highest sensory level was $125.6 \pm 16.5$, which was comparable to our study Various studies have stated Intrathecal small dose of dexmedetomidine used in combination with Ropivacaine for spinal anaesthesia have been shown to produce a shorter onset of motor block and a prolongation in duration of motor and sensory block. By virtue of its effects on spinal $\alpha 2$ receptors, said benefits are known to occur when used with local anesthetics for neuraxial blocks.

Kosugi et al., examined the effects of dexmedetomidine on compound action potential (CAP) recorded from frog sciatic nerve and found that CAPs were inhibited by $\alpha 2$ adrenoceptor agents so that they were able to block nerve conduction.Yoshitomi et al., demonstrated that dexmedetomidine enhanced the local anesthetic action of local anaesthetics via peripheral $\alpha-2 \mathrm{~A}$ adrenoceptors.

In a study by Atul Kumar Singh (2012-2014), they evaluated the efficacy of two different doses of dexmedetomidine as an adjuvant to isobaric ropivacaine, intrathecally. Time to achieve desired block was least in with Dexmedetomidine of $5 \mu \mathrm{g}$ and maximum in group Dexmedetomidine of 10 $\mu \mathrm{g}$. The sensory-motor blockade remained significantly prolonged in later group with Dexmedetomidine of $10 \mu \mathrm{g}$.

\section{Effect on Pain score}

Intrathecal $\alpha_{2}$-receptor agonists have been found to have antinociceptive action for both somatic and visceral pain. Their analgesic action is a result of depression of the release of $\mathrm{C}$-fiber transmitters and hyperpolarisation of postsynaptic dorsal horn neurons. ${ }^{[9]}$

In our study, mean highest pain score on VAS was $4.9 \pm 0.8$ for only Ropivacaine group and 
$3.8 \pm 0.66 \quad$ for Ropivacaine with Dexmedetomidine group. This difference was statistically significant. In study by Alka Shah et al,mean highest pain score on VAS was $4.4 \pm 1.4$, which was higher than our score, yet comparable. We found, mean time of required for first dose of rescue analgesia was $244.33 \pm 2.83$ minutes for only Ropivacaine group and $466.23 \pm 2.4$ minutes for Ropivacaine with Dexmedetomidine group. This difference was statistically significant. In study by Alka Shah et al,mean time of required for first dose of rescue analgesia was $478.4 \pm 20.9$, which was comparable to our study .

Number of Diclofenac injections in first $24 \mathrm{hrs}$ postoperatively was $3.73 \pm 0.64$ for only Ropivacaine group and $1 \pm 0.59$ for Ropivacaine with Dexmedetomidine group. This difference was statistically significant. In study by Alka Shah et al,number of Diclofenac injections in first 24 hrs postoperatively was $0.97 \pm 0.19$, which was comparable to our study .

Naithani Udita et al assessed dose dependent effect of dexmedetomidine ( $3 \mathrm{mcg}$ vs $5 \mathrm{mcg}$ ) as an adjunct to isobaric ropivacaine in spinal anesthesia. They found third of their cases required analgesic supplementation. Both doses of dexmedetomidine produced a similar effect on block characteristic and postoperative analgesia; however, a dose of $5 \mathrm{mcg}$ dose was associated with more hypotension and sedation.

\section{Effects on Hemodynamics}

In our study, Blood pressure and Heart rate were significantly lower in Ropivacaine with Dexmedetomidine group compared to only Ropivacaine group (Table). In our study, highest and Lowest Systolic Blood pressure recorded was $115.93 \pm 4.83 \mathrm{mmHg}$ and $107.38 \pm 3.67 \mathrm{mmHg}$ respectively at 180 minutes and 10 minutes post dosing. In study by Alka Shah et al, Highest and Lowest Systolic Blood pressure recorded was 111 \pm 5.74 and $94.08 \pm 5.80$ respectively at 1 minutes and 10 minutes post dosing. Findings of both studies were comparable.
In our study, highest and Lowest Diastolic Blood pressure recorded was $73.59 \pm 4.26$ and $67.1 \pm$ 5.41 respectively, at 180 minutes and 10 minutes post dosing. In study by Alka Shah et al, Highest and Lowest Systolic Blood pressure recorded was 74. $56 \pm 6.12$ and $65.36 \pm 4.92$ respectively, at 1 minutes and 10 minutes post dosing. Findings of both studies were comparable.

In our study, highest and Lowest heart recorded was $80.21 \pm 4.14$ and $70.62 \pm 6.29$ respectively, at 180 minutes and 20 minutes post dosing. In study by Alka Shah et al, highest and Lowest heart recorded was $98.5 \pm 4.16$ and $80.64 \pm 3.05$ respectively, at 2 minutes and 60 minutes post dosing.

\section{Conclusion}

Dexmedetomidine $(5 \mu \mathrm{g})$ as an adjunct to Ropivacaine is superior to Ropivacaine alone in intrathecal analgesia .It augments onset of action , prolongs sensory blockade and reduces requirement rescue analgesics. Though it may cause alterations in hemodynamic, it can be reversed with vasopressors. However, clinical studies to prove its efficacy and safety and varying dosages for supplementation of spinal local anaesthetics are recommended.

\section{Limitation of the study}

Duration of surgery and blood loss were not considered in our study.

\section{Ethical committee approval}

Taken

\section{Financial support and sponsorship}

Nil

\section{Conflicts of interest}

There are no conflicts of interest

\section{Bibliography}

1. Al-Mustafa MM, Abu-Halaweh SA, Aloweidi AS, Murshidi MM, Ammari BA, Awwad ZM, et al. Effect of dexmedetomidine added to spinal bupivacaine for urological procedures. Saudi Med J. 2009;30:365-70. 
2. Kim JE, Kim NY, Lee HS, Kil HK. Effects of intrathecal dexmedetomidine on low-dose bupivacaine spinal anesthesia in elderly patients undergoing transurethral prostatectomy. Biol Pharm Bull. 2013; 36:959-65.

3. Al-Ghanem SM, Massad IM, Al-Mustafa MM, Al-Zaben KR, Qudaisat IY, Qatawneh AM, et al. Effect of adding dexmedetomidine versus fentanyl to intrathecal bupivacaine on spinal block characteristics in gynecological procedures: A double blind controlled study. Am J Appl Sci. 2009;6:882-7.

4. Dobrydnjov I, Axelsson K, Thörn SE, Matthiesen P, Klockhoff H, Holmström B, et al. Clonidine combined with small-dose bupivacaine during spinal anesthesia for inguinal herniorrhaphy: A randomized double-blinded study. AnesthAnalg. 2003; 96:1496-503

5. Förster JG, Rosenberg PH. Small dose of clonidine mixed with low-dose ropivacaine and fentanyl for epidural analgesia after total knee arthroplasty. Br J Anaesth. 2004;93:670-7.

6. Tan JA, Ho KM. Use of dexmedetomidine as a sedative and analgesic agent in critically ill adult patients: A metaanalysis. Eur J Anaesthesiol. 2011;28:3-6

7. Kanazi GE, Aouad MT, Jabbour-Khoury SI, Al Jazzar MD, Alameddine MM, AlYaman R, et al. Effect of low-dose dexmedetomidine or clonidine on the characteristics of bupivacaine spinal block. Acta Anaesthesiol Scand. 2006; 50:222-7.

8. Gupta R, Bogra J, Verma R, Kohli M, Kushwaha JK, Kumar S. Dexmedetomidine as an intrathecal adjuvant for postoperative analgesia. Indian J Anaesth. 2011;55:347-51.
9. Mantouvalou M, Ralli S, Arnaoutoglou H, Tziris G, Papadopoulos G. Spinal anesthesia: Comparison of plain ropivacaine, bupivacaine and levobupivacaine for lower abdominal surgery. Acta Anaesthesiol Belg. 2008;59:65-71

10. Alka Shah, Ila Patel, Rachana Gandhi . Haemodynamic effects of intrathecal dexmedetomidine added to ropivacaine intraoperatively and for postoperative analgesia. Int J Basic ClinPharmacol. 2013 Feb;2(1):26-29

11. Kosugi T, Mizuta K, Fujita T, Nakashima M, Kumamoto E. High concentrations of dexmedetomidine inhibit compound action potentials in frog sciatic nerves without $\alpha_{2}$ adrenoceptor activation. British Journal of Pharmacology. 2010;160(7):1662-1676.

12. Yoshitomi T, Kohjitani A, Maeda S, Higuchi H, Shimada M, Miyawaki T. Dexmedetomidine enhances the local anesthetic action of lidocaine via an alpha2A adrenoceptor.AnesthAnalg. 2008 Jul; 107(1):96-101.

13. Singh AK, Singh Y, Jain G, Verma RK. Comparison of two different doses of intrathecal dexmedetomidine as adjuvant with isobaric ropivacaine in lower abdominal surgery. Anesthesia, Essays and Researches. 2015;9(3):343-347.

14. Naithani Udita, MeenaMahendra Singh, Gupta Sunanda, MeenaKhemraj, Swain Lalatendu, Pradeep D S. Dose-dependent effect of intrathecal dexmedetomidine on isobaric ropivacaine in spinal anesthesia for abdominal hysterectomy: Effect on block characteristics and hemodynamics. Journal Ans clinPharmac .2015;31:72-9. 